\title{
SENY Y RAUXA EN RAMON LLULL Y FRANCESC EIXIMENIS
}

\author{
Seny and Rauxa in Ramon Llull and Francesc Eiximenis
}

\author{
Agustí Boadas Llavat \\ Universidad Ramon Llull (Barcelona)
}

\section{RESUMEN}

La filosofía romántica caracteriza a la manera de ser catalana con dos palabras: seny, o sentido común, y rauxa, o arrebato. Buscando las raíces de esta caracterización, encontramos dos pensadores franciscanos, el beato Ramon Llull y fray Francesc Eiximenis, representando estas tendencias. A través de sus vidas y escritos, se intentará recoger lo que se puede decir al respecto.

Palabras clave: Filosofía catalana, Seny, Rauxa, Ramon Llull, Francesc Eiximenis.

\begin{abstract}
Romantic Philosophy characterizes the way of being Catalan with two main words: seny, common sense, and rauxa, or rapture. Looking for the roots of this characterization, we find two Franciscan thinkers, blessed Ramon Llull and Brother Francesc Eiximenis, representing these tendencies. Through his life and writings, we try to collect what can be said about it.
\end{abstract}

Keywords: Catalan Philosophy, Seny, Rauxa, Ramon Llull, Francesc Eiximenis.

\section{LOCOS Y RACIONALISTAS}

Suele creerse, porque así se define a sí mismo, que el beato Ramon Llull era un foll, un loco. También es común considerar a fray Francesc Eiximenis su antagonista, el máximo representante de lo que se ha llamado el seny catalán, con permiso de san Ramon de Penyafort. ${ }^{1}$ Sin embargo, este encasillamiento, aunque útil, suele esconder más problemas que soluciones. La taxonomía acostumbra a ser ventajosa en el campo de las ciencias naturales, pero es especialmente oscura en las ciencias del espíritu. Leamos un ejemplo: «¿No es verdad que los mallorquines son superiores a los barceloneses en sutileza de espíritu y agudeza de ingenio?» - dice un gerundense como Eiximenis, torturador de cuerpos y almas. ${ }^{2}$

Se ha querido asociar, también, ambos conceptos a lo más intrínseco del espíritu catalán, aquél que se ha querido enraizar en Llull y Eiximenis. Y es que responden a una realidad

1 Cf. Mensa, J., Introducció a la filosofía medieval, Bellaterra, Universitat Autònoma de Barcelona Servei de Publicacions, 2012, pp. 203-218.

2 Puig, J., ed., Nicolau Eimeric. Diàleg contra els lul·listes, Barcelona, Quaderns Crema, 2002, p. 77: «iI no és veritat que els mallorquins són superiors als barcelonins en subtilitat d'esperit i agudesa d'enginy?» Sobre el falsario inquisidor, puede verse: Perarnau, Josep, De Ramon Llull a Nicolau Eimeric, Barcelona, Facultat de Teologia de Catalunya, 1997. 
histórica que puede rastrearse en los albores del romanticismo de la Renaixença, preparada por Balmes y caracterizada sobre todo por la literatura de Maragall, Folch i Torres, Josep Abril, o Torres i Bages. ${ }^{3}$ ¿Y qué decir de la arquitectura modernista, mezcla de cordura burguesa y desmesura artística? Con todo, según Eugeni d'Ors hay que advertir que el tema puede ser tan sólo una anécdota elevada a categoría (como, añadiríamos, el proverbial estoicismo español, heredado de las máximas senecanas). El resultado, no obstante, nos abre una sugerente reflexión sobre la historia de la filosofía medieval que nos transporta a una fecundidad que trataremos de esbozar brevemente. ${ }^{4}$

Y lo primero que hay que hacer es intentar acotar los términos. La palabra seny suele traducirse por sensatez, sentido común o cordura. De origen incierto, suele asociarse a refranes, dichos y sentencias que intentan reflejar un pretendido Geist catalán que hunde sus raíces en el nacimiento de la lengua, en el cristianismo medieval. Sin embargo, la primera vez que se utiliza es en un contexto juglaresco. En efecto, Cerverí de Girona (1259-1281), en sus Proverbis, reconoce:

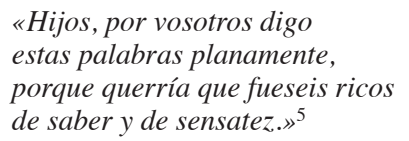

La palabra también evoca la idea de orden, de pragmatismo y de molicie ante lo establecido. Poner seny es poner racionalidad, algo así como aplicar el criterio de Balmes. Algo así, pero muy diferente, según se mire, a lo que los franceses llaman sagesse y los ingleses common sense. Al mismo tiempo, se asocia también a ser realista. En definitiva, pues, resuena en el término aquel aristotelismo descafeinado que sería el del sentido común. Aunque nada tenga que ver con la parte del conocimiento que reúne los cinco sentidos en uno, como veremos.

Por su parte, la palabra rauxa deriva del latín rixa (disputa, discusión o riña) y también del rauja provenzal (rabia). Como antónimo del seny, la rauxa viene a ser una determinación no meditada, un impulso irreflexivo, un acto de furia. También corresponde a la boutade francesa, la ocurrencia, tan propia de anecdotarios y chistes. Y ¿por qué no? al entusiasmo, algo así como la borrachera del espíritu o el exceso furioso. Ejemplos de ella son los episodios de la historia catalana más revolucionarios: la Guerra de los Segadores o el 1714. Así Jaume Vicens Vives los define como arrebatos: ${ }^{6}$

3 Son clásicas las Proses de bon seny de Joan Raventós o las Historietes exemplars de Josep Maria Floch i Torres.

4 Udina Cobo, J. M., «Ejemplificación medieval de la interrelación teoría-praxis (de Escoto Eriúgena a Anselmo de Canterbury, con Agustín de fondo)», en J. M. Ayala, ed., Actas del II Congreso de Filosofía Medieval, Zaragoza, Sociedad de Española de Filosofía Medieval, 1996, p. 512: «Olvidar la mutua y polivalente relación que existe entre pensamiento (seny) y vida (rauxa), entre especulación y compromiso, entre teoría y dimensión noteórica, nunca puede resultar tan fecunda como tener en cuenta una tal interrelación, e incluso buscarla siempre. Y no es sólo que sin ella no hay filosofía, sino que tampoco puede hacerse historia de la filosofía sin tener en cuenta dicha relación». Visitado por la hermana muerte corporal, sean estas palabras homenaje a él (1939-2014) y a su padre, Frederic Udina Martorell (1914-2011), eximio medievalista.

5 Fills, per vosaltres dich / aquests dits planamen, / car volgra fossets richs / de saber e de seny (Proverbi núm. 12), citado en: Riquer, M. de, Historia de la literatura catalana, vol. I, Barcelona, Ariel, 1993, p. 158.

6 «Ésser arrauxat és, precisament, estar mancat de seny, obeir els impulsos emocionals, actuar segons determinacions sobtades. En aquestes circumstàncies ens deixem portar per la passió, sense sospesar les realitats ni mesurar-ne les conseqüències. Llavors som els homes de la flamarada i de les actituds extremistes. El nostre sentit d'ironia falla, i sortim al carrer devorats per un excés de pressió sentimental. L'arrauxament és la base psi- 
«Ser arrauxat es, precisamente, andar falto de seny, obedecer a impulsos emocionales, actuar según determinaciones repentinas. En estas circunstancias nos dejamos llevar por la pasión, sin sopesar las realidades ni mesurar sus consecuencias. Somos entonces los hombres de la llamarada y de las actitudes extremistas. Nuestro sentido de la ironía nos falla y salimos a la calle devorados por un exceso de presión sentimental. El arrauxament es la base psicológica de las acciones subversivas catalanas, la justificación histórica del todo o nada, la negación del ideal de compromiso y pacto dictada por la sensatez colectiva».

En cambio, para Josep Ferrater Mora, ante la circunspección como prudencia realista y la mesura, valor mediterráneo, contrapuesto a la grandeza quijotesca y a cualquier romanticismo (recordemos la descomunal influencia del wagnerianismo en la Barcelona de comienzos del siglo XX), no existe la rauxa como categoría filosófica. ${ }^{7}$ Para Esquirol, además, se esconde una tradición de corte platónico, retomada por los estoicos, san Agustín o Pascal, que incide en el tema del cuidado del alma. ${ }^{8}$

He aquí, pues, una primera caracterización del tema en general. Caso de creer que haya una especificidad en la filosofía catalana, dejando de lado si ésta está escrita en catalán, español o latín, conviene rastrear sus supuestos orígenes a través de dos de sus figuras más notables, las cuales, además, provienen de un marcado acento franciscano y se circunscriben en un momento filosófico especialmente interesante del pensamiento medieval: la atomización de las escuelas y la especialización de lo que hoy podríamos llamar el oficio del intelectual.

\title{
2. DE ERASMO A LOS JUGLARES
}

\begin{abstract}
«Después de éstos vienen los filósofos, cuya barba y amplia capa les hace venerables, los cuales se tienen por los únicos sabios y al resto de los mortales consideran sombras errantes. Con qué manso delirio construyen infinitos mundos, se entretienen en medir como a pulgada y con un hilo el Sol, la Luna, las estrellas y los planetas; explican las causas del rayo, del viento, de los eclipses y de todos los demás fenómenos inexplicables, sin ninguna vacilación, como si fuesen secretarios del artífice del mundo y hubiesen acabado de llegarnos del consejo de los dioses. En tanto, la naturaleza se ríe en grande de ellos y de sus conjeturas, pues nada absolutamente saben con certeza, y buena prueba de ello son esas disputas interminables que sostienen acerca de los asuntos más sencillos. Aunque nada sepan, creen saberlo todo y no se conocen a sí mismos, ni ven la fosa abierta a sus pies, ni la roca en que pueden tropezar, sea a les veces porque son cegatos y otras porque tienen la cabeza a pájaros. Ello no les impide afirmar que ven claras las ideas, los universales, las formas abstractas, las quididades, los primeros principios, las ecceidades, $\mathrm{y}$, en fin, con-
\end{abstract}

cològica de les accions subversives catalanes, la justificació històrica del tot o res, la negació de l'ideal de compromís i pacte dictat pel seny col·lectiu» (Vicens i Vives, J., Notícia de Catalunya, Barcelona, Ed. Destino, 1954, p. 221).

$7 \quad \mathrm{Ni}$ la locura por quijotismo prudente. A lo más que llega es al romanticismo y al espíritu dionisíaco: Ferrater Mora, J., Les formes de la vida catalana i altres assaigs, Barcelona, Edicions 62, 1980, pp. 65 y 74. No olvidemos, sin embargo, que Vicens Vives parece haberle leído con avidez, ya que la obra de Ferrater Mora fue publicada en 1944.

8 «Mi buen amigo, siendo ateniense, la ciudad más grande y renombrada en sabiduría y poder, ¿no te avergüenzas de afanarte por aumentar tus riquezas todo lo posible, así como tu fama y honores, y, en cambio, no te preocupas ni interesas por la sensatez y la verdad y por cómo tu alma va a ser lo mejor posible?» (Apología de Sócrates, Platonis Opera I, Oxford, Oxford University Press, Classical Texts, 1995, 29d6-e3). Esquirol, J. M., La resistencia íntima, Barcelona, Acantilado, 2015, p. 68. 
ceptos tan sutiles, que el mismo Linceo no llegaría a percibir, según creo. Desprecian al vulgo profano, porque ellos se sienten capaces de trazar triángulos, rectángulos, círculos y semejantes figuras geométricas superpuestas las unas a las otras y en forma laberíntica o rodeadas de letras puestas como en formación y repetidas en diversas filas, con cuyas tinieblas oscurecen a los indoctos. Entre estos filósofos se cuentan también los que anuncian lo porvenir tras consultar los astros y prometen prodigios más que mágicos, y todavía tienen la suerte de encontrar a quienes lo creen.» ${ }^{9}$

Erasmo de Rotterdam decía esto en 1509, a instancias de un terciario franciscano, santo Tomás Moro, con el que acababa de traducir al humorista Luciano de Samósata. En el texto, merece destacarse una doble referencia: por un lado a los escotistas parisinos y por el otro al beato Ramon Llull, con cuyas tinieblas oscurecen a los indoctos. Así parece ser el autor del Ars Magna, un lulista del XVI que transcribe el Ars demonstrativa, que empieza con las figuras de la forma de recordar, entender y querer. ${ }^{10}$ Antes, sin embargo, de publicarse en 1511, la obra erasmista tuvo sus precedentes: el cardenal franciscano Cisneros hizo divulgar, en la recién inaugurada Universidad de Alcalá de Henares, obras de Llull y parece que en 1510, en la Valencia del impresor Joan Jofre, aparecía el Instrumentum cuiusdam, la Sentencia definitiva, en la que, teóricamente, se desacreditaba la funesta acción de Nicolás Eimeric ${ }^{11}$ y se retornaba la doctrina luliana a su prístino estado. Podemos preguntarnos, pues, con toda legitimidad, si este ataque de Erasmo responde al propio beato o a los lulistas de su tiempo. Lo que sí sabemos es que los pobres escotistas se habían extraviado por el laberinto de las sutilidades y de las más variopintas discusiones bizantinas. ${ }^{12}$

En el otro extremo temporal, encontramos a los juglares y a la poesía mística, especialmente musulmana. Los unos, con el amor furioso; y los otros, con el éxtasis espiritual, practicando la escritura automática, como hizo Yalal ad-Din Muhammad Rumi (1207-1273). ${ }^{13}$ En ambos casos no podemos dejar de ver un cierto paralelismo con el Llibre d'Amic $i$ Amat. Tampoco se nos escapa la paradójica situación del juglar, a la vez músico y poeta, que tiene que reducir su inspiración a la métrica:

«Con gusto compondría una canción nueva, que fuese agradable, si pudiera.

Pero la razón gobierna

mi canto y le da impulso.» ${ }^{14}$

9 Erasmo de Rotterdam, Elogio de la locura LII, Madrid, Espasa Calpe, 1958. Edición de Pedro Voltes Bou, p. 99-100.

10 Bonner, A., Raimundo Lulio. Ars Magna, Madrid, Ed. Patrimonio Nacional, 1990, p. 5.

11 Ramon Llull goza de una excelente lista para el inquisidor: «cuya doctrina contiene más de quinientos errores, aunque sólo transcribo cien» (Sala-Molins, L., ed., Nicolau Eimeric y Francisco Peña, El Manual de los inquisidores, Barcelona, Muchnick Editores, 1983, p. 42).

12 Un ejemplo: Etzkorn, G. J., ed., De arcanis Dei. Card. Bessarion eiusque socii anno 1471 disputantes..., Roma, Miscellanea Francescana, 1997.

13 Dice el fundador de los derviches giróvagos en su Diván: «No tengo cuerpo ni alma, pues pertenezco al alma del Amado» (Rubayat, trad. directa de C. Janés y A. Taherí, Madrid, Ediciones del Oriente y el Mediterráneo, 1996, p. 45).

14 «Volotièrs faria / tal chançon novèla, que fos agradiva / si far la podia. / Ras rasons capdèla / mon chant e l'abriva». Poema de Guiraut Riquièr (muerto en Narbona en 1292) escrito en 1276, año precisamente en que Lull funda Miramar desde Narbona. Sobre la falta de rigor en el ámbito juglaresco, véase: Fernández de la Cuesta, I. y Lafont, R., Las cançons dels trobadors, Toulouse, Institut d'Estudis Occitans, 1979, p. 28; para el poema, cf. p. 696. Y para un análisis de lo que significó Miramar, véase: Actas del II Congreso Internacional de Lulismo I, Palma de Mallorca, Maioricensis Schola Lullistica, 1979. 
No caigamos en la tentación, sin embargo, de asociar rauxa con amor heroico, sino más bien asociarla con el amor furioso, como el de Roldán. ${ }^{15}$

Tal vez, sin embargo, en la raíz de la concepción del amor luliano y eiximeniano haya que poner al juglar de Dios, san Francisco y a sus primeros compañeros. No en vano, entre los juglares encontramos a los franciscanos fray Jofre de Foixà († 1295), autor de Vers et regles de trobar, y fray Matfre Ermengaud († Béziers, 1288). Y más tarde al célebre fray Anselm Turmeda ${ }^{16}$, autor de la Disputa del asno.

Por otro lado, no deja de ser indicativo que tanto Llull como Eiximenis recojan una idea propia de la Ilustración: la enseñanza y el enciclopedismo. Si el siglo XIII es el de la explosión de la universidad, también lo es el de la ignorancia: hay que reformar los planes de estudio para desasnar a la burguesía y a los mismos estudiantes. Tomemos un texto precursor: «Es, pues, escaso y vil lo que no se entiende sino que se cree, y mucho más lo que se ignora. Y porque respecto de lo que cree el hombre quedan infinitas cosas que ignora (sin duda las más grandes, mejores y más bellas), es un loco quien hace de ellas ostentación e intenta divulgar su ciencia como si fuera portentosa. $\rangle^{17}$

\section{LA VIDA DE RAMON LLULL}

Blanquerna (1283), que incluye el Llibre d'amic i amat, ${ }^{18}$ es el primer gran escrito luliano de éxito en su tiempo. ${ }^{19}$ En él aparece, justamente, un juglar, al que Blanquerna dice: «El oficio de juglaría fue creado con buena intención, a saber, para loar a Dios y para dar solaz y consuelo a los que están atribulados y atormentados en servir a Dios». ${ }^{20}$ Pero esta definición parecería no tener nada que ver con el inicio de la Vida coetánea, donde el propio terciario franciscano reconoce que de joven era trovador, es decir, poeta en lengua vulgar, y juglar si

15 Cf. Mensa, J., «L'experiència espiritual d'Arnau de Vilanova i el rebuig del coit terapèutic en el tractament de l'“amor heroicus"», Revista Catalana de Teologia, 32 (2007), pp. 143-52.

16 Una perla anselmiana: vuestros simples e ignorantes (Tuhfa, p. 452 de la edición de Míkel de Epalza, Madrid, Hiperión, 1993). Se trata de los sabios cristianos. Es evidente la ironía: san Francisco se definía a sí mismo como simple e ignorante, indicando de este modo que no quería hacer teología como los profesionales. Arnau de Vilanova, por su parte, retoma el tema: «Cristo ilumina a los simples e idiotas que tienen celo de Él» (De mysterio cymbalorum, 101-102; citado por Mensa, J., Arnau de Vilanova [c. 1240-1311], Madrid, Ediciones del Orto, 1998, p. 66).

17 Extraído de su Opus Majus, I, 12-22: Boadas, A., Roger Bacon: subjectivitat i ètica, Barcelona, Ed. Herder, 1996, p. 87. Llull montó el convento franciscano de Miramar, que duró unos quince años; consiguió del Concilio de Vienne en 1311 la creación de colegios de idiomas, que tuvieron que esperar hasta la fundación de Alcalá de Henares casi dos siglos después; y deja escrito el tratado pedagógico Blanquerna, una verdadera enciclopedia del saber; por su parte, Eiximenis, con su Crestià aspiraba a un nuevo orden social y religioso a través, por decirlo así, de una enciclopedia popular (cf. Renedo, X., «Notes sobre la datació del Dotzè del Crestià de Francesc Eiximenis», Annals de l'Institut d'Estudis Gironins, 52 (2011), pp. 208-209).

18 Cf. Serverat, V., «El Llibre d'amic i amat de Ramon Llull: modesta contribución al estudio de sus fuentes», Revista Española de Filosofía Medieval, 5 (1998), pp. 41-60.

19 Cf. sobre la vida y obra del beato: Bordoy, A., La filosofía de Ramon Llull, Mallorca, Objeto Perdido, 2011; Batllori, M., Ramon Llull i el lul.lisme, Barcelona, Bibilioteca d'estudis i investigacios 3i4 19, 1993; Xirau, J., Vida y obra de Ramón Llull, Barcelona, Orión, 1946; Rubio, J. E., Les bases del pensament de Ramon Llull, València, Biblioteca Sanchís Guarner, 1997; Butiñá, J., Los mundos de Ramón Llull, Madrid, UNED, 2012; Llinarès, A., Ramon Llull, Barcelona, Edicions 62, 1968; Bonner, A., y Badia, L., Ramon Llull, Vida, pensament $i$ obra literària, Barcelona, Les Naus d'Empúries, 1988.

20 «De la fin del llibre... L'ufiçi de juglaría fo atrobat per bona entenció, ço és a saber, per loar Déu e per donar solaç e consolació a aquells qui són treballats e turmentats en servir Déu» (Soler, A., ed., Ramón Llull. Blanquerna, Barcelona, Ed. Barcino, 1995, p. 146. 
además interpretaba sus composiciones. ${ }^{21}$ En cambio, sí es una definición que enlaza directamente con los textos sanfranciscanos. ${ }^{22}$ Poco después, en 1287, envía un grupo de obras, consciente de que «liber iste scandallum ex nomine libri qui intitulatur Ars demonstrativa in cordibus in ipso legentium». ${ }^{23}$ ¿Moderará Llull este escándalo o, más bien, mantendrá esa rauxa? Ya antes, en su Llibre de l'orde de cavalleria, de 1276, dice que se ganan más batallas con maestría y cordura que por acopio de tropas. ${ }^{24}$

Entre las muchas paradojas que la lectura del beato mallorquín provoca, hay algunas que debieran ser resaltadas. Una de ellas, sobre la primacía del racionalismo sobre el fideísmo (o viceversa), merece ser destacada en primer lugar. ${ }^{25} \mathrm{Si}$ acentuamos la parte racional, sea a través de las razones necesarias, sea a través de lo que se ha llamado escolasticismo popular, nos encontramos con un filósofo que poco o nada se diferencia de un averroísta, real o ficticio, al que Llull desprecia desde sus contactos parisienses. $\mathrm{Si}$, en cambio, acentuamos a un misionero y a un loco, nos encontramos que poco o nada entenderemos obras como el Llibre del gentil e dels tres savis ${ }^{26}$ o la Disputatio fidei et intellectus. ${ }^{27}$ De hecho, un segundo contrasentido sería preguntarse por qué abandona el Arte y deriva hacia el árbol de las ciencias, de forma parecida al de fray Roger Bacon, en una evolución que tiene un punto de inflexión decisivo en su polémica sobre el averroísmo. ${ }^{28}$ Y, en tercer lugar, Ramon Phantasticus ¿es un loco, un antojadizo, un visionario, un idealista, un iluminado, un místico, un utópico? ${ }^{29}$ También aquí aparecen los averroístas.

¿Quiénes son? La respuesta histórica parecería ser un constructo mental luliano. Respondamos, simplemente y para entendernos, que son los malos filósofos, es decir, los aristotélicos. A medida que el Doctor Arcangélico avanza en su contacto con París, va descubriendo el sacrosanto templo del saber medieval y no le gusta. Encuentra en la universidad poca piedad, entendida como sentimiento religioso. Los teólogos son profesionales del artificio racional y Dios, la excusa perfecta para una especulación casi infinita. Vaya por delante, sin embargo, que él mismo admite los principios aristotélicos en el caso, por ejemplo, del sentido común o potencia sensitiva. ${ }^{30}$ Así, el seny es equivalente a sentido aristotélico; pero también es lo con-

21 Cf. Ramon Llull, Vida de mestre Ramon, a cura d'Anthony Bonner, Barcelona, Editorial Barcino, 2013, p. 38 .

22 Sobre el franciscanismo de Llull, véase: Cabot Rosselló, S., Inicis del convent de Sant Francesc $i$ relacions de Ramon Llull amb els franciscans, Mallorca, Publicacions de l'Institut Teològic de Mallorca, 2008.

23 Badia, L., y Soler, A., eds., Intel-lectuals i escriptors a la Baixa Edat Mitjana, Barcelona, PAM, 1994, p. 50.

24 Cf. Ramon Llull, Libro de la orden de caballería, edición bilingüe, Barcelona, Real Academia de Buenas Letras, 1901, p. 58.

25 Cf. Colomer, E., «El problema de la relació fe-raó en Ramon Llull: proposta de solució», en: Actes del Simposi Internacional de Filosofia de l'edat mitjana, Vic, Patronat d'Estudis Osonencs, 1996, pp. 15-19; Llinàs, Carles, «Ramon Llull (1232-1316)», en: Història del pensament cristià, Barcelona, Proa, 2002, pp. 365-366. Baste añadir un libro que domestica Llull a parámetros tomistas: Bové, S., El sistema científico luliano, Barcelona, Tipografía Católica, 1908.

26 Cf. Ramon Llull, Llibre del gentil e dels tres savis, Palma, NEOL, 2001, pp. 143-152.

27 Cf. Ramon Llull, Disputa entre la fe i l'enteniment, Barcelona, Brepols, 2011.

28 Cf. Carreras y Artau, T. y J., Historia de la filosofía española I, Barcelona - Girona, Institut d'Estudis Catalans - Diputació de Girona, 20012, p. 422; Boadas, A., Roger Bacon: subjectivitat i ètica, pp. 206-210. Dice Bacon: «Pienso que la sabiduría sin elocuencia es como una espada afilada en manos de un paralítico, igual que la elocuencia que no tiene sabiduría es como una espada en manos de un loco» (Opus Tertium 4; ibíd., p. 95).

29 Cf. Colomer, E., «El problema de la relació fe-raó en Ramon Llull», pp. 15-19; Llinàs, C., «Ramon Llull (1232-1316)», pp. 365-366.

30 Cf. Bonnner, A., y Ripoll, M. I., Diccionari de definicions lul-lianes. Dictionary of Lullian Definitions, Barcelona, Col-lecció Blanquerna 2, 2002, pp. 271-271. Sobre las referencias a seny en concreto: Colom Mateu, M., Glossari General Lul·lià V, Mallorca, Editorial Moll, 1985, p. 80. 
trario de locura: perder el sentido, volver a tener sentido, estar ebrio... Lo podemos encontrar en el siguiente texto, donde las facultades del alma, entendimiento, memoria y voluntad son puestas en relación con el seny:

«54. Iba el amigo por una ciudad como un loco, cantando a su Amado; y la gente le preguntó si había perdido la cordura. Y respondió que su Amado le había arrebatado su querer y que él le había dado su entendimiento; por eso, se había quedado sólo con el recuerdo, con el que recordaba a su Amado.» ${ }^{31}$

¿Qué podría molestar en especial del averroísmo al Beato? Lo encontramos en su Declaratio Raymundi de 1297, donde, a partir de la condena de 1277 del obispo de París, Esteban Tempier, hace un comentario a sus artículos. Tomemos cuatro y veremos cuán alejados están de su óptica:

«Los discursos de los teólogos se fundan sobre fábulas.

Nada se sabe de más cuando se sabe teología.

Los sabios del mundo son sólo los filósofos.

La religión cristiana impide aprender.

Se posee la felicidad en esta vida y no en la otra.» ${ }^{32}$

Y eso, sin mencionar ¡la eternidad del mundo!

Ramon el Fantástico acaba su vida entre la utopía presentada al Concilio de Viena y sus viajes misioneros. Yendo al concilio, sin embargo, topó con un padre conciliar que explotó en risas: «Ya creía yo que eras algo fantástico, pero ahora veo que estás loco de atar». ${ }^{33}$ Eso puede situarse en 1311. El Desconhort, de 1305 seguramente, es sombrío y pesimista: el piadoso palmesano habla locamente y dicen que está loco. ${ }^{34} \mathrm{O}$, más bien, ¿tendríamos que referirnos a que es un extravagante, un pensador que está fuera de los círculos oficiales del poder intelectual de su tiempo?

\section{EIXIMENIS (1330-1409)}

Suele caracterizarse a fray Francesc Eiximenis como el clásico representante del seny. Sus obras catalanas así lo acreditan y doscientos manuscritos y una veintena de incunables lo confirman. ${ }^{35}$ El pactismo, ${ }^{36}$ tan característico de su obra, se circunscribe en la tradición que llegará hasta el Renacimiento, de obras dedicadas al buen gobierno, como el De regimine

31 Ramon Llull, Llibre d'amic e amat, «54: Anava l'amic per una ciutat con a foll, cantant a son amat; e demanaren-li les gents si havia perdut son seny. Respòs que son amat havia pres son voler, e que ell li havia donat son enteniment; per açò era-li romàs tan solament lo remembrament, ab què remembrava son amat».

32 «152: Quos sermones theologi fundati sunt in fabulis. 153: Quod nichil plus scitur propter sicre theologiam. 154: Quod sapientes mundi sunt philosophi tantum. 175: Quod lex christiana impedit addiscere. 176: Quod felicitas habetur in ista vita, et non in alia» (Piché, D., La condamnation parisienne de 1277, Paris, Vrin, 1999, pp. $124-126$ y 132).

33 Cf. Sureda, F., El Beato Ramón Llull, Madrid, Espasa-Calpe, 1934, p. 338. El original latino dice: phantasticissimum (Ramon Llull, El fantàstic. La ciutat del món, Barcelona, Brepols, 2008, p. 112).

34 Cf. Colomer, E., De la Edad Media al Renacimiento, Barcelona, Herder, 2012, pp. 41-42 (la primera edición es de 1975); véase, también, Id., El pensament als Països Catalans durant l'Edat Mitjana i el Renaixement, Barcelona, IEC - PAM, 1997.

35 Cf. Libera, A. de, Pensar en la Edad Media, Barcelona, Anthropos, 2000, pp. 54-55.

36 Cf. Webster, J., Francesc Eiximenis. La societat catalana al segle XIV, Barcelona, Edicions 62, 1967, pp. 15-16; Cervera Vera, L., Francisco de Eiximenis y su sociedad urbana ideal, Madrid, Swan, 1989, pp. 138-139. 
principum de fray Pedro de Aragón o incluso el Príncipe de Maquiavelo. Sin embargo, hay un Eiximenis reformador, apasionado e influenciado por ideas más universales, fruto de su estudio en Oxford. Allí comparte aula con fray John Wycliff, escuchando lecciones de escotismo y nominalismo. Eiximenis no esconde su admiración por las obras de Arnau de Vilanova e interviene en la vida social de su tiempo como el hombre del seny y como el hombre de la nueva espiritualidad burguesa. Sobre su actitud profética, bástenos decir que sospechamos que el hecho de mencionar a Arnau de Vilanova, fray Pedro de Aragón o fray Juan de Rocatalhada, obedece más a una estrategia de reforma moral y religiosa (tanto de reforma de las costumbres de la sociedad como de autenticidad de los sentimientos cristianos en un tiempo, el del Cisma, tan tormentoso) que a una convicción íntima. ${ }^{37}$ Así, por ejemplo, con el tiempo, renuncia a la división ternaria de la historia a favor de la septenaria. ${ }^{38}$

Un ejemplo de ello lo podemos rastrear en el tema de la su supuesta misoginia. Lejos ya de los tiempos en que el respeto a la mujer era algo mayor, el polígrafo gerundense se adapta a los nuevos tiempos, donde las mujeres irán pasando de ser imagen y semejanza divinas a ser consideradas sólo en su función reproductora, como se advierte en la represión protestante de las brujas del siglo XVI, pocos años después de la versión castellana de Lo Libre de les Dones, el Carro de las donas. La posición eiximeniana está lejos de la misoginia de Jaume Martorell y algunos humanistas como Bernat Metge, y lejos también de la invectiva antifenenina catalana del maldit. Está, por decirlo así, en un punto intermedio. ${ }^{39}$ Puede verse esto en su consideración del pecado de Eva: perdió tanto el juicio que en las mujeres reina la pasión y la carnalidad, pues nada las detiene.

«Ítem, ço diu, per tal cant axí follament se ach, en fer contra Déu sens tot conseyll del marit, qui era ductor e regidor seu, per tal fo ferida per lo cap de dret en dret, e perdé tant de seny que és tan poch aquell qui y és romàs que no és quays res. E d'aquesta pèrdua tan gran li ve que la dona no ha fre quaix negú en ses passions; e con la carn sia tota corrompuda en natura humana, axí con dit és, seguex-se que en la dona regnen les passions e malícies e malvestats de la carn, puys no y ha fre qui les tempra. E aquesta és, ço diu, la rahó per què les dones són comunament revesses, car segueixen les passions corporals qui són contràries a la raó natural.» ${ }^{40}$

O, en la versión castellana:

«Y porque ella consejo a su marido que comiesse del fruto, aviéndoselo Dios dado por consejero y tutor, que por presumir de consejera le quitó Dios el seso, y así es muy liviana y sin juyzio la mujer. Y dize más, que por haver la mujer menospreciado la recti-

37 Cf. Carreras y Artau, T., Fray Francisco Eiximenis. Su significación religiosa, filosófico-moral, politica y social, Girona, Anales del Instituto de Estudios Gerundenses, 1946, pp. 13-14.

38 El P. Josep Maria Pou no lo salva de ser visionario, alquimista, supersticioso y crédulo. Cf. Pou, J. M., Visionarios, beguinos y fraticelos catalanes (siglos XIII-XV), en edición de A. Hauf, Alicante, Instituto de Cultura «Juan Gil-Albert», Diputación Provincial, 1996, pp. 576-583; en edición de Madrid, Editorial Cisneros, 1991, pp. 410-415. Llull, hay que decir, también participaba de la división en siete edades: Doctrina Pueril, Palma, NEORL, 2005, pp. 270-273.

39 Cf. P. Nolasc del Molar, O.F.M.Cap., Eiximenis, Olot, Biblioteca Olotina, 1962, p. 17; Renedo, X. y Gascon, S., Francesc Eiximenis. Prosa, Barcelona, Ed. Teide, 1993, p. 17; Eiximenis, F., Estetica medievale. Dell'eros della mensa e de la città, Milán, Jaca Book, 1986, pp. 12-14. Añadamos, como curiosidad, que Arnau de Vilanova incluye a santa Ángela de Foligno (1248-1309), maestra de teólogos, como ejemplo de mujer santa, en una obra que parece anterior a su muerte, la Allocutio christini: Vilanova, Arnau de, La prudència de l'escolar catòlic $i$ altres escrits, Barcelona, Proa, 2002, pp. 197-198.

40 Eiximenis, Francesc, Lo libre de les dones I, Barcelona, Curial, 1981, p. 21. 
tud de la razón y conciencia y el hermoseo ornamento de virtudes con que Dios la crió, que por esta causa le dio Dios que siempre sea menospreciada de qualquier ante quien ella se quisiere hazer estimar y honrrar.» ${ }^{41}$

Para percatarnos de cómo soslaya el tema, sigue en el capítulo siguiente añadiendo que nadie debe hablar mal de las mujeres, ya que así lo hacen los herejes, los traidores, los ladrones y los usureros (robadors). Y también pueden verse, con sorpresa, las diferencias entre el original y la traducción.

Otro ejemplo de la sutileza de Eiximenis, basada en su extraordinaria percepción de la realidad, su formación académica y su sentido común, lo podemos encontrar en su descripción del pecado y cómo afecta a la naturaleza humana. Y aquí hemos de retroceder a san Buenaventura, que nos ilustra en la idea de que el hombre es algo más que cuerpo y espíritu. «Y el hombre, con el ojo de la carne puede ver lo que hay fuera de él, con el de la razón lo que hay en él y con el de la contemplación lo que está sobre él». ${ }^{42}$ El Obispo de Elna dedica sendos capítulos a los efectos del pecado en el entendimiento, la voluntad, la inclinación moral al bien, la conciencia y la libertad. ${ }^{43}$ Antes ya había dicho que la segunda razón de la maldad era la locura o el poco sentido común (poch seny) ${ }^{44}$. Y así la locura (oradura) se divide en la fantasía (y aquí se incluye también el don de profecía), los pecadores (que no han perdido el sentido común, sino que son maliciosos) y los rabiosos (furiosos). ${ }^{45}$

Finalmente, hay una larga serie de publicaciones que contienen sentencias, cuentos y fábulas. Citemos tres, que van seguidas, y que muestran ambos extremos, seny y rauxa en el franciscano: «Loco es quien quiere más allá del poder, y más loco es quien otorga. Si fuerza con sentido común tiene guerra, la fuerza se va a tierra. La carne hace carne y el pan panza; pero el vino lleva a la danza». ${ }^{46} \mathrm{El}$ sentido común ${ }^{47}$ y el saber, en definitiva, son para el fraile una obra de caridad que no puede esconderse. ${ }^{48}$ En fin, como concluye la asamblea de los animales: «l'home és molt cortès animal». ${ }^{49}$

41 Clausell Nácher, C., Carro de las donas. Valladolid, 1542. Adaptación del Llibre de les dones de Francesc Eiximenis O.F.M. realizada por el P. Carmona O.F.M. I, Salamanca - Madrid, Universidad Ponticia de Salamanca - Fundación Universitaria Española, 2007, pp. 161-162.

42 San Buevanentura, Breviloquio, edición de J. Gómez Chao, Madrid, BAC Selecciones 16, 2015, p. 79. Cf., también: El gobierno del alma, 2 (Bonaventura, Soliloqui i altres escrits, Barcelona, Proa, 1994, pp. 217-219).

43 Cf. Eiximenis, Francesc, Terç del cristià III, Barcelona, Ed. Barcino, 1932, pp. 88-105.

44 Cf. Eiximenis, Francesc, Terç del cristià I, Barcelona, Ed. Barcino, 1932, pp. 262-263.

45 Cf. Eiximenis, Francesc, Dotzè llibre del cristià II.2, Girona, Col·legi Universitari de Girona y Diputació de Girona, 1987, pp. 524-525.

46 Eiximenis, Francesc, Sapienciari, Barcelona, Johan Batlle, 1900, Fol. VIv-VIIr. En cuanto a otros: Gascón, S., «El voltor en el Llibre dels àngels d'Eiximenis. Una àpoca de 1398», en: Actes del X Congrés Internacional de l'Associació Hispànica de Literatura Medieval, Alicante, Institut Interuniversitari de Filologia Valenciana, 2005, pp. 793-808; Viera, D. J., «El hombre cuerdo no debe fiar de la mujer ningún secreto» como tema de la literatura clásica hispana, Bogotá, Instituto Cano y Cuervo, 1975; Viera, D. L., «L'humor en les obres de Francesc Eiximenis», Boletín de la Real Academia de Buenas Letras de Barcelona, 39 (1983-1984), pp. 157-175; Eiximenis, Francesc, Contes i faules, Barcelona, Els nostres clàssics, 1925; Eiximenis, Francesc, Exemples i faules, Barcelona, GEA Edicions, 1989.

47 Cf. Eiximenis, Francesc, Dotzè llibre del cristià II.2, Girona, Col·legi Universitari de Girona y Diputació de Girona, 1987, pp. 524-525.

48 Quod debet prudenter vivere (Eiximenis, Francesc, Psalterium alias Laudatorium, Toronto, Pontifical Institute of Mediaeval Studies, 1988, p. 235).

49 Cf. Eiximenis, Francesc, Terç del cristià I, Barcelona, Ed. Barcino, 1932, p. 250. 


\section{CONCLUSIÓN}

Las trayectorias vitales e intelectuales de Llull y Eiximenis no permiten, después de esta breve presentación, ni convertirlos en padres del seny ni de la rauxa, ni articular un discurso filosófico especial sobre el tema. Más bien, con los textos dispersos, en esta presentación, nos quedamos ayunos de buscar más y encontrar respuestas más satisfactorias. Aún así, podemos comprobar que representan un acercamiento a la escolástica tan sugerente como provechoso, acostumbrados como estamos a leer o bien todos los textos en clave teológica, o bien en clave especulativa.

No sabremos si es constitutivo del espíritu catalán tener a la vez seny y rauxa, pero sí nos habrá enriquecido ver cómo unos autores nos ofrecen una filosofía viva, vibrante, a veces oscurecida por el hollín de los siglos y lo rancio del lenguaje, pero luminosa si se sabe contextualizar. Pongamos, pues, un ejemplo final: « $i$ Qué aburrida es la vida presente! — decía una bella dama, amparada a la sombra de un árbol en un verde prado rodeado de fuentes. Y es triste porque la doncella, llamada filosofía de amor, tiene pocos amantes, mientras que su hermana, filosofía de saber, los tiene innumerables». ${ }^{50}$ Hoy sospechamos que no son tantos; porque, en definitiva, como Llull y Eiximenis muestran, más allá del lenguaje, de cualquier lenguaje, más allá de saber, de cualquier saber, de cualquier filosofía, el seny y la rauxa son partes integrantes de nuestra vida, conforman nuestra moral en el sentido de las cosas de la vida práctica, del amor y sus derivados. Como tal vez diga el ruiseñor: Si no nos entendemos por lenguaje, entendámonos por amor. ${ }^{51}$

bibliotecaprovincial@franciscans.cat

Fecha de recepción: día 29 de junio de 2015

Fecha de aceptación: día 9 de septiembre de 2015

50 Cf. Ramon Llull, Filosofia d'amor, prólogo.

51 Llull, Ramon, Llibre d'amic e amat 27: «Cantava l'aucell en lo verger de l'Amat. Vénc l'amic, qui dix a l'aucell: -Si no ens entenem per llenguatge, entenem-nos per amor, cor en lo teu cant se representa a mos ulls mon Amat». 